\title{
CONSUBSTANCIALIDADE: UMA REFLEXÃO CONCEITUAL PARA PESQUISAS EM PUBLICIDADE
}

\author{
Consustancialidad: una reflexión conceptual para la \\ investigación publicitaria
}

\author{
Consubstanciality: a conceptual reflection for advertising \\ research
}

\author{
Carolina Minuzzi \\ Universidade Federal de Santa Maria, Santa Maria, Brasil \\ Mestra em Comunicação pela UFSM, pós-graduada em Marketing pela UFRGS, publicitária, partici- \\ pante do grupo Nós - Pesquisa Criativa (UFSM). E-mail: carolinammurari@gmail.com
}

\author{
Juliana Petermann \\ Universidade Federal de Santa Maria, Santa Maria, Brasil \\ Doutora em Ciências da Comunicação pela Universidade do Vale do Rio dos Sinos (UNISINOS). \\ Possui graduação em Comunicação Social - Publicidade e Propaganda pela UFSM, mestrado em \\ Linguística Aplicada pela UFSM. Professora do programa de Pós-Graduação em Comunicação da \\ UFSM. Coordenadora do grupo Nós - Pesquisa Criativa. E-mail: petermann@ufsm.br
}

RESUMO O objetivo deste artigo é discutir as possibilidades conceituais de uso do conceito da consubstancialidade nas pesquisas em publicidade. Dessa forma, iremos (a) discorrer sobre a importância dos marcadores sociais da diferença; (b) comparar os conceitos de consubstancialidade e interseccionalidade; e (c) apontar as situações mais adequadas para o uso do termo consubstancialidade. A partir de um resgate histórico conceitual com base em Kergoat, entendemos que, ao analisar as práticas de trabalhadores em publicidade, a consubstancialidade é uma alternativa fértil, já que parte da compreensão materialista histórica e das relações sociais fundamentais (de gênero, classe e "raça") em toda sua complexidade e dinâmica, sendo fundamental para pesquisas que abordam questões de gênero na publicidade.

PALAVRAS-CHAVE Comunicação, Publicidade e propaganda, Consubstancialidade, Questões de gênero.

RESUMEN El propósito de este artículo es discutir las posibilidades conceptuales en torno al uso del concepto de consustancialidad en la investigación publicitaria. De esta manera, (a) discutiremos la importancia de los marcadores sociales de diferencia; (b) compararemos los conceptos de consustancialidad e interseccionalidad; y (c) señalaremos las situaciones más adecuadas para utilizar el término de consustancialidad. A partir de un rescate histórico conceptual con base en Kergoat, entendemos que, al analizar las prácticas de los trabajadores en publicidad, la consustancialidad es una alternativa fecunda, ya que parte de la comprensión histórica materialista y también de las relaciones sociales fundamentales (de sexo, clase y "raza"), en toda su complejidad y dinámica, siendo fundamental para las investigaciones que abordan cuestiones de género en la publicidad.

PALABRAS-CLAVE Comunicación, Publicidad, Consustancialidad, Temas de género. 
ABSTRACT This article aims to discuss the conceptual possibilities regarding the use of the concept of consubstantiality in advertising research. Thus, we will (a) discuss the importance of the social marks of difference; (b) compare the concepts of consubstantiality and intersectionality; and (c) to point out the most appropriate situations for using the term of consubstantiality. From a conceptual historical rescue based on Kergoat (2010), we understand that when analyzing the practices of workers in advertising, consubstantiality is a fertile alternative, since it starts from the historical materialist understanding and also from the fundamental social relations (of sex, class and "race"), in all complexity and dynamics, being fundamental for researches that address gender issues in advertising.

KEYWORDS Communication, Advertising, Consubstantiality, Gender issues.

\section{INTRODUÇÃO}

O engendramento dos marcadores sociais das diferenças entre os seres humanos é de grande relevância para as pesquisas nas áreas das ciências humanas e sociais, pois articula distanciamentos e proximidades entre as pessoas. Quando focamos na área de publicidade, esse processo proporciona um olhar curioso a partir das fronteiras invisíveis, mas estabelecidas, entre quem exerce essa profissão.

A partir dessa inquietação, este artigo traz à luz o conceito da consubstancialidade e pretende discutir as possibilidades de relacioná-lo às pesquisas em publicidade. Assim, o problema que guia este estudo é: de que maneira é possível empregar o conceito da consubstancialidade nas pesquisas em publicidade? Entendemos que nosso objetivo geral é discutir as possibilidades conceituais em relação ao uso desse termo (KERGOAT, 2010) nas pesquisas em publicidade. Para isso, estabelecemos os seguintes objetivos específicos: (a) discorrer sobre a importância dos marcadores sociais da diferença; (b) comparar os conceitos de consubstancialidade e interseccionalidade; (c) apontar a ou as situações mais adequadas para o uso do conceito da consubstancialidade nas pesquisas em publicidade.

A preocupação com a noção da consubstancialidade se dá pela amplitude de termos utilizados por autoras e autores nos estudos de gênero, também nos estudos em publicidade. Piscitelli (2008), por exemplo, afirma que algumas autoras trabalham com o termo “categorias de articulação”, como bell hooks, em 1981. Outro termo que costuma ser utilizado é interlocking oppressions, que pode ser traduzido como "entrelaçamento de opressões", utilizado por autoras como Patricia Hill Collins (2000) e Wendy Hulko (2009). Já no Brasil, segundo Henning (2010), é possível encontrar uma pequena variação gráfica no termo intersecção, sendo aceitável a palavra "interseção", sem alteração no sentido. Em relação ao termo "consubstancialidade”, desenvolvido por Kergoat (2010), as relações sociais são entendidas a partir da coextensividade, definindo seu lócus de atuação enquanto conceito, distanciando-se dos demais já mencionados.

Diante das várias termologias utilizadas nos estudos de gênero, torna-se necessário situar o conceito da consubstancialidade nos estudos em publicidade, facilitando seu uso e colaborando, mesmo que de forma sucinta e modesta, para o fortalecimento do debate de gênero nas pesquisas em publicidade. Dessa forma, neste artigo, nos referimos à publicidade a partir do conceito de sistema publicitário elaborado por Trindade (2017), que faz referência ao conjunto de práticas relacionadas ao exercício da profissão publicitária, contemplando a área acadêmica 
e a área mercadológica. Esse termo é responsável por englobar todos outros conceitos que descrevem o cenário brasileiro em relação à publicidade e à propaganda.

Partimos do pressuposto que o sistema publicitário se materializa através de profissionais que exercem a atividade de publicidade no mercado de trabalho; de docentes e discentes, que ensinam e estão em processo de aprendizagem sobre a profissão; dos próprios produtos publicitários, que são resultados de todo o envolvimento entre profissionais da área e anunciantes; e, ainda, destacamos as pessoas que ocupam a esfera da recepção, que estão cada vez mais presentes na produção das mensagens publicitárias, principalmente por meio das mídias digitais. Portanto, utilizamos o conceito de sistema publicitário a partir da compreensão da variedade de termos existentes, e principalmente por sua abrangência diante das questões contemporâneas da própria publicidade.

Após posicionar o conceito de sistema publicitário, vale resgatar alguns dados que mostram um recente estreitamento entre os estudos de gênero a partir do campo acadêmico da publicidade. Segundo o mapeamento de Tomazetti (2019), que apresenta a intersecção das pesquisas de pós-graduação em comunicação no Brasil com a temática de gênero, das 326 pesquisas encontradas entre os anos de 1976 até 2015, apenas 26 são sobre publicidade e gênero. Porém, em outro estudo, Minuzzi e Petermann (2020) identificaram 48 pesquisas que engendram publicidade e gênero, de 2016 a 2019, produzidos pela pós-graduação no Brasil, mostrando aumento de mais de $84 \%$ no último período. Mesmo com desse crescimento, entendemos a necessidade de explorar a relação entre gênero e o sistema publicitário, principalmente diante da complexidade dessa relação.

Mesmo que, à primeira vista, pareça um assunto esgotado, principalmente diante da repetição dos achados das pesquisas em relação à falta de representatividade das mulheres em propagandas, é urgente estudar as questões de gênero a partir dessa área, especialmente se estendermos nosso olhar para outras instâncias do sistema publicitário (TRINDADE, 2015), como a da produção. Outras pesquisas nos ajudam entender a importância de observar situações que acontecem no mercado de trabalho da publicidade, mas que nem sempre são analisadas no campo acadêmico, possibilitando reflexões mais aprofundadas. Minuzzi (2020) discorre sobre a trajetória invisibilizada das mulheres profissionais de publicidade, principalmente quando são acionadas os marcadores de raça e classe. Hansen e Weizenmann (2015) abordam o ambiente masculinizado das áreas de criação em agências de propaganda, o que acaba afastando mulheres criativas desse setor. Diante disso, o autor e autora comentam sobre a figura masculina do criativo, que muitas vezes é criada desde a graduação, com professores e referências de profissionais homens, como reforça Petemann (2011).

Dessa forma, acreditamos que discorrer sobre conceitos importantes, como o da consubstancialidade, é necessário para o desenvolvimento de pesquisas em publicidade que abordem as questões do feminino, do masculino e/ou de todas as performances de gênero (BUTLER, 2003), relacionando-as a outros marcadores sociais.

Portanto, estruturamos este artigo da seguinte forma: realizamos uma breve revisão histórica sobre as questões de gênero, apresentando como se deu o engendramento dos marcadores sociais das diferenças a partir dos estudos feministas; discorremos sobre os conceitos de interseccionalidade e consubstancialidade, a fim de pontuar as principais diferenças, 
respondendo aos objetivos específicos apontados; para analisar o uso do conceito da consubstancialidade, utilizamos documentos referentes ao sistema publicitário, apresentados no Quadro 1, e que foram escolhidos segundo os seguintes critérios: matérias de revistas, jornais, site e/ou report que discorrem legitimamente sobre publicidade; documentos publicados a partir de 2015.

Quadro 1. Principais materiais selecionados para as análises.

\begin{tabular}{|l|l|}
\hline Nome do material & Fonte e ano \\
\hline $\begin{array}{l}\text { Matéria sobre "Participação feminina na } \\
\text { liderança das agências" }\end{array}$ & $\begin{array}{l}\text { Realização e divulgação: Propmark e More } \\
\text { Grls (SPAULUCCI, 2020) }\end{array}$ \\
\hline Report "Hostilidade, Silêncio e Omissão" & Grupo de Planejamento (2017) \\
\hline Matéria com Maíra Liguori & Meio e Mensagem (SACCHITIELLO; LEMOS, 2016) \\
\hline Matéria com Keka Morelle & $\begin{array}{l}\text { Globo.com } \\
\text { (5 PERGUNTAS..., 2019) }\end{array}$ \\
\hline Matéria com Joana Mendes & Universa Talks (2020) \\
\hline
\end{tabular}

Fonte: Elaborado pelas autoras.

A análise documental foi a técnica escolhida para explorar esses dados a partir do conceito da consubstancialidade elaborado por Kergoat (2010), que faz pensar nas disputas das relações sociais a partir dos três imperativos materialistas: disputas entre os gêneros na divisão sexual do trabalho, a historicidade e a hierarquização da divisão sexual do trabalho. Após as análises, fizemos nossas considerações finais, levantando os principais pontos discutidos no artigo e, principalmente, respondendo ao nosso problema de pesquisa, de forma a contribuir com o campo científico da comunicação e da publicidade.

\section{A IMPORTÂNCIA DO ENGENDRAMENTO DOS MARCADORES SOCIAIS DA DIFERENÇA}

Ao analisarmos os documentos e arquivos (FOUCAULT, 1976) divulgados sobre o movimento das mulheres desde o sufrágio, é possível observar uma trajetória perpassada pelas questões sociais de raça e classe, para além das questões de gênero. Mesmo que o termo da interseccionalidade tenha sido utilizado pela primeira vez apenas em 1989, e o conceito da consubstancialidade em 2010, Sojouner Truth já relatava as diferenças entre as mulheres negras, brancas e pobres em 1851, na Convenção dos Direitos das Mulheres realizada em Ohio, a partir de seu famoso discurso conhecido como "E eu não sou mulher?".

Davis (1981) comenta que as primeiras movimentações das mulheres do norte do globo estavam diretamente relacionadas à luta abolicionista, o que levou mulheres brancas a aderirem às posturas antirracistas quando perceberam que também pertenciam a um grupo considerado oprimido, já que eram “escravas” de uma vida de matrimônio, sem legitimidade de fala e de escolhas. 0 envolvimento com a revolução abolicionista motivou a mobilização desse grupo em prol dos direitos civis. A participação delas na organização de manifestações e convenções políticas alavancou o desenvolvimento 
de habilidades, principalmente discursivas, que foram cruciais para a organização do movimento feminista.

Contudo, nem todas as mulheres brancas foram tocadas pelo movimento antiescravagista, havendo disputas entre as pautas dentro do próprio contexto feminista, como ressalta Davis (1981). Para Patricia Hill Collins (2000, p. 3), houve historicamente "descontinuidades na tradição do pensamento das mulheres afro-americanas”, alternando momentos de possibilidades de expressão e momentos de silenciamento de suas manifestações. Essas interdições discursivas (FOUCAULT, 1976) fizeram com que os saberes negros não se consolidassem nas sociedades ocidentais, enfraquecendo seus discursos, inclusive dentro do próprio movimento feminista.

No Brasil, Sueli Carneiro popularizou a expressão "enegrecendo o feminismo", com o objetivo de "marcar a identidade branca e ocidental na formulação clássica feminista, [...] e revelar a insuficiência teórica e prática política para integrar as diferentes expressões do feminino construídas em sociedade multirraciais e pluriculturais” (CARNEIRO, 2019, p. 273).

Assim, o termo interseccionalidade passa a ser uma alternativa para marcar as diferenças sociais nos estudos de gênero. Kimberlé Crenshaw foi quem o utilizou pela primeira vez, em 1989, de forma metafórica, e se empenhou em desenvolvê-lo em 1994, no texto "Mapeando as margens: interseccionalidade, políticas de identidade e violência conta as mulheres não-brancas”. De modo geral, a interseccionalidade leva ao deslocamento da obrigatoriedade de partir de um marcador específico para desenvolver a análise, mas dedica atenção localizada às configurações de diferenciações sociais e possíveis desigualdades em termos contextualizados histórica e culturalmente (CRENSHAW, 1994). Piscitelli (2008) resume o conceito de interseccionalidade e a forma como é empregado na atualidade:

A proposta de trabalho com essas categorias [interseccionalidade, categorias de articulação] é oferecer ferramentas analíticas para apreender a articulação de múltiplas diferenças e desigualdades. É importante destacar que já não se trata da diferença sexual, nem da relação entre gênero e raça ou gênero e sexualidade, mas da diferença, em sentido amplo, para dar cabida às interações entre possíveis diferenças em contextos específicos. (PISCITELLI, 2008, p. 266)

No entanto, a possibilidade de múltiplas entradas para se articular análises sobre gênero, entre outros aspectos, gerou críticas no campo acadêmico, fazendo com que novos conceitos fossem desenvolvidos, como é o caso do conceito da consubstancialidade, desenvolvido por Danièle Kergoat. A pesquisadora francesa ressalta que "interseccionalidade” é um termo oriundo das áreas exatas, mais precisamente da geometria, e sua simples transposição para as ciências sociais e humanas implicaria em sérios problemas analíticos. Segundo Kergoat, "pensar em termos de cartografia nos leva a naturalizar as categorias analíticas [...]. Dito de outra forma, a multiplicidade de categorias mascara as relações sociais. [...] [As posições] não são fixas; por estarem inseridas em relações dinâmicas, estão em perpétua evolução e renegociação" (KERGOAT, 2010, p. 98).

Hirata (2014) comenta três pontos em que Danièle Kergoat questiona a interseccionalidade: (a) a multiplicidade de pontos de entrada que a interseccionalidade permite, para além das relações de gênero, raça 
e classe, como casta, religião, nação, entre outros. Essa característica leva a um perigo de fragmentação das práticas sociais e à dissolução da violência das relações sociais, com o risco de contribuir para sua reprodução; (b) para a autora, não é certo que todos esses pontos remetem a relações sociais e talvez não seja o caso de colocá-los todos num mesmo plano; (c) por fim, para Kergoat, as e os teóricos da interseccionalidade continuam a raciocinar em termos de categorias, e não de relações sociais, privilegiando umas em detrimento de outras, a exemplo da noção de classe à de religião, de sexo à casta etc., sem historicizá-las, e por vezes sem levar em conta as dimensões materiais da dominação.

Danièle Kergoat é uma pesquisadora comprometida com o tema da divisão sexual do trabalho e criou o termo "consubstancialidade" a partir de suas críticas à interseccionalidade. Assim, entendemos a necessidade de explorar esse conceito, avaliando-o em relação às pesquisas em publicidade, principalmente àquelas que desejam observar as profissionais publicitárias, imersas nas relações de trabalho no sistema publicitário.

\section{CONSUBSTANCIALIDADE PARA OS ESTUDOS DE PUBLICIDADE}

O termo consubstancialidade foi desenvolvido pela socióloga feminista francesa Danièle Kergoat e é formado a partir de três relações sociais: gênero, "raça" e classe, que são consideradas relações de produção'. Segundo a autora, são nessas relações que há o entrecruzamento de exploração, dominação e opressão. Kergoat (2010) esclarece que sua maneira da apreender os fenômenos sociais parte da perspectiva materialista, histórica e dinâmica, discorrendo sobre a consubstancialidade dessas relações sociais a partir de uma propriedade essencial: a coextensividade.

Kergoat (2010) afirma que as relações sociais são consubstanciais, formando um nó que não pode ser desatado no nível das práticas sociais. Assim, as relações de gênero, "raça” e classe são coextensivas, que se desenvolvem, se reproduzem e se coproduzem mutuamente. A autora exemplifica seu pensamento comentando sobre a participação de mulheres no mercado de trabalho, em que mesmo com o aumento do número de trabalhadoras, a desigualdade salarial persiste. Além disso, o trabalho doméstico ainda é desempenhado majoritariamente por mulheres, o que mantém a segregação entre os ofícios masculinos e femininos:

O capitalismo tem necessidade de uma mão-de-obra flexível, que empenhe cada vez mais sua subjetividade: $O$ trabalho doméstico assumido pelas mulheres libera os homens e, para as mulheres de alta renda, há a possibilidade de externalização do trabalho doméstico para outras mulheres. (KERGOAT, 2010, p. 2)

A importância do entendimento do conceito de relações sociais para a consubstancialidade está no poder de ação dos grupos que compõem essas relações. As relações intersubjetivas são aquelas próprias dos indivíduos concretos entre os quais se estabelecem. As relações sociais, por sua vez, são abstratas e opõem grupos sociais em torno de uma disputa. A distinção

1. Segundo Kergoat (2010), as relações sociais como produto das relações de produção são aquelas determinadas pela estrutura econômica presente na sociedade. 
entre relação intersubjetiva e relação social permite compreender que, se a situação mudou em matéria de relações intersubjetivas, nas relações sociais, continuam a operar e a se manifestar sob suas três formas canônicas: exploração, dominação e opressão, que podem ser ilustradas pelas diferenças salariais, pela maior vulnerabilidade e maior risco de ser vítima de violências (KERGOAT, 2010).

A partir dessa breve explanação, entendemos que é possível acionar a consubstancialidade nas pesquisas de publicidade que se referem às profissionais publicitárias e/ou trabalhadoras da indústria de comunicação. Isso porque o conceito nasce do entendimento de que as relações sociais de gênero, "raça" e classe são analisadas a partir do imperativo materialista de como se dá a apropriação do trabalho de um grupo por outro, o que nos obriga, segundo Kergoat (2010), a pensar nas disputas das relações sociais. Por exemplo, no que concerne ao gênero, são formadas pela divisão do trabalho entre os sexos e o controle social da sexualidade e da função reprodutiva das mulheres.

Ao observar o sistema publicitário, é possível identificar as disputas das relações sociais de gênero formadas pela divisão sexual do trabalho nos dados sobre liderança nesse segmento do mercado. Segundo dados levantados pela Propmark, juntamente com o coletivo More Grls, a participação feminina é minoria na liderança criativa das agências. Os números da pesquisa, publicada em março de 2020, revelam que as mulheres totalizavam $46 \%$ do quadro geral de funcionários. As que ocupam cargos de liderança, ou seja, da diretoria para cima, representam $44 \%$. Mas, quando considerado o topo, o índice despenca: são 37\% nos cargos executivos ou de vice-presidentes, chegando a apenas $10 \%$ na presidência, e esse número cai para 4,3\% quando o recorte é mulheres negras.

Outro aspecto que marca as disputas entre os gêneros está na correlação entre liderança e assédio. Segundo a pesquisa "Hostilidade, Silêncio e Omissão”, realizada pelo Grupo de Planejamento de São Paulo em 2017, nas principais agências de publicidade de São Paulo, 90\% das mulheres entrevistadas já sofreram algum tipo de assédio, moral ou sexual. Entre as respondentes, 51\% foram assediadas sexualmente no ambiente de trabalho. Desse número, 39\% dos casos envolveram contatos físicos. Esse dado fica ainda mais marcado em Minuzzi (2020), que discorre sobre o afastamento das práticas de assédio à medida que mulheres publicitárias vão ascendendo na profissão, justamente porque se torna mais difícil assediar uma pessoa com concentração de poder. A dificuldade para as mulheres trabalhadoras conquistarem espaços de liderança acaba afetando as relações de trabalho, principalmente porque os cargos privilegiados são ocupados pelo gênero masculino, deixando as trabalhadoras mais vulneráveis.

Um dos fatores visto como empecilho para mulheres chegarem à liderança no sistema publicitário é a maternidade. Maíra Liguori, cofundadora da ONG Think Olga e da consultoria Think Eva, comenta em entrevista ao Meio e Mensagem sobre o difícil ajuste entre a rotina em agências e o trabalho doméstico, que ainda é atribuído às mulheres: "Nas agências existe a cultura de que quanto mais horas a pessoa trabalha, mais valorizada ela é. Para a mulher, que geralmente tem de conciliar a carreira com a rotina de casa e com a maternidade, aquilo se torna inviável" (SACCHITIELLO; LEMOS, 2016).

A divisão sexual do trabalho, que ainda direciona mulheres para serviços domésticos, derivada da noção de maternidade, pode vir a afastar mulheres que se especializaram em mercados dinâmicos, como 
o da publicidade. A mulher é sobrecarregada pela jornada contínua de trabalho, que começa no emprego e continua no ambiente doméstico, com o papel de esposa e mãe. Assim, as mulheres publicitárias enfrentam dificuldades em articular todas essas tarefas e ainda em assumir espaços de liderança, como comenta Keka Morelle, atual chefe de criação da Wunderman Thompson: "Esse lugar de vulnerabilidade para mim hoje é trabalhar e ser mãe [...], o simples horário de reunião que mudou, uma concorrência que exige um trabalho no fim de semana, tudo interfere diretamente na rotina de casa" (5 PERGUNTAS..., 2019).

Diante dessas questões que ainda mantêm as mulheres nos trabalhos domésticos, principalmente aqueles que envolvem o cuidado e a organização familiar, mesmo aquelas que desejam ingressar no mercado de trabalho em ambientes profissionais - seja por necessidade financeira, seja por desejo de emancipação - enfrentam jornadas excessivas de trabalho (profissional e doméstica), afetando sua carga mental (MINUZZI, 2020). De modo geral, a falta de participação do homem em tarefas domésticas e na criação das crianças e a maior valorização do trabalho masculino nos espaços profissionais fazem com que as mulheres, principalmente negras, continuem na base do mercado de trabalho do sistema capitalista contemporâneo.

Outro imperativo materialista que faz pensar as disputas das relações sociais, segundo Kergoat (2010), é o histórico. Para a autora, as relações devem ser historicizadas, pois há uma estrutura que permite sua permanência, mas também passam por transformações, que correspondem a períodos históricos e eventos que podem acelerar seu curso. No entanto, Kergoat (2010) salienta que não se deve jamais historicizar uma relação social em detrimento de outras. Isso significaria transformar a relação em categorias caracterizadas pela metaestabilidade.

Nesse contexto, é pertinente mencionar a desproporcionalidade entre a presença de mulheres brancas em relação às mulheres negras no sistema publicitário. Como os dados levantados apontam, a presença feminina é minoria na liderança criativa das agências, e ao direcionamos o olhar para mulheres negras, é ainda menor, tanto em cargos de liderança quanto no mercado como um todo. Na pesquisa da Propmark com o More Grls, fica evidente que, quando o assunto é raça, as mulheres negras estão muito longe de ocuparem espaços de poder na criação publicitária brasileira: "Apenas 4,3\% das afrodescendentes estão no comando de alguma área. Ou seja, mesmo que $44 \%$ dos cargos de liderança sejam ocupados por mulheres, 96,7\% delas são brancas” (SPAULUCCI, 2020).

Um exemplo da disparidade entre a presença de mulheres brancas e negras em cargos de liderança da indústria criativa pode ser notada pelo recorte temporal. Segundo Minuzzi (2020), em 1978, a profissional Hilda Schültzer se tornou a primeira mulher presidente de uma grande agência de publicidade no Brasil, a CBBA. Ainda antes da virada do século, já era possível encontrar outras mulheres brancas em cargos de liderança, mesmo que em número desproporcional em relação aos homens, e praticamente todas da alta sociedade brasileira, diplomadas em faculdades, bilíngues e com experiências internacionais (MINUZZI, 2020). Já a primeira diretora de criação negra de uma grande agência no Brasil chegou ao posto apenas em 2020: a publicitária Joana Mendes, que se reconhece como lésbica e feminista.

Esse exemplo nos leva a pensar na importância do movimento feminista negro como potencializador dos eventos atuais, bem como Kergoat (2010) comenta, acelerando a inserção das mulheres negras 
no mercado de trabalho formal, e aqui, em especial, o da publicidade. Em entrevista, Joana Mendes relata que é neta de trabalhadora doméstica negra, e que graças à postura da avó optou por sair do Norte do Brasil e se especializar em uma área mais intelectualizada, e não do care: "Nós, em geral, costumamos ir para as profissões de cuidado, mesmo quando podemos fazer uma universidade. Ir para uma profissão elitista, como é a publicidade, na qual os profissionais demoram a ganhar dinheiro, foi um privilégio que a minha avó me deu” (ELA SE TORNOU..., 2020).

O terceiro imperativo materialista que faz pensar as disputas das relações sociais, segundo Kergoat (2010), são os princípios da separação e da hierarquização da divisão sexual do trabalho. Por mais que as formas dessa divisão sejam instáveis no tempo e no espaço, o trabalho do homem sempre foi distinto do trabalho da mulher, e, por consequência, sempre obteve mais reconhecimento, "valendo" mais do que as funções desempenhadas por mulheres.

Anteriormente mencionamos sobre a desigualdade entre homens e mulheres, e entre mulheres brancas e negras no que diz respeito à ocupação de cargos de liderança no sistema publicitário. E agora cabe ressaltar a figura do "publicitário criativo", ou do "homem criativo".

A área de criação publicitária tem grande prestígio no mercado de trabalho, e sempre foi ocupada majoritariamente por homens. Ainda conforme a pesquisa da Propmark e do More Grls (2020), no Brasil, os homens ocupam $75 \%$ dos cargos de chefia na criação, contra $25 \%$ de mulheres. Para além dos dados do mercado, a figura masculina e criativa do publicitário já é referência a ser seguida na academia. Hansen e Weizenmann (2015) identificaram mecanismos comunicativos, no âmbito do mercado publicitário e nas instituições de ensino superior, que legitimam a criação publicitária como um espaço de atuação masculino, configurando a divisão sexual do trabalho e a reprodução da dominação masculina. Assim, o pesquisador e a pesquisadora comentam que as rotinas e os horários estendidos da criação não favorecem a rotina das mulheres, que ainda são responsáveis pelas atividades ligadas ao lar e à maternidade.

Ainda, as instituições de ensino superior também são responsáveis por institucionalizar e legitimar a supremacia masculina na área de criação. Autores dos livros utilizados em sala de aula e personalidades da área de criação tidas como referência são homens, na maioria das vezes (PETERMANN, 2011). Assim, "de forma não deliberada, os cursos de graduação em publicidade e propaganda consagram o imaginário do criativo-homem” (HANSEN; WEIZENMANN, 2015, p. 11).

Diante desses três imperativos materialistas, conseguimos entender o conceito de relações sociais para Kergoat (2010, p. 2) e como ele está imerso no conceito da consubstancialidade, ou seja, "uma relação social é uma relação antagônica entre dois grupos sociais, instaurada em torno de uma disputa". Assim, o conceito da consubstancialidade é o entrecruzamento dinâmico e complexo do conjunto dessas relações, cada uma imprimindo sua marca nas outras, se ajustando e construindo de maneira recíproca.

Mas o fato de as relações sociais formarem um sistema não exclui a existência de contradições entre elas. Kergoat (2010) traz a metáfora da espiral, que serve para dar conta do fato de que a realidade não se fecha em si mesma. Portanto, não se trata de fazer um tour de todas as relações sociais envolvidas, uma a uma, mas de enxergar os entrecruzamentos e as interpenetrações que formam um "nó" no seio de uma individualidade ou de um grupo. Quanto à coextensividade, 
aponta para o dinamismo das relações sociais, procura dar conta do fato de que as elas se produzem mutuamente.

Para exemplificar a consubstancialidade das mulheres trabalhadoras em sociedades ocidentais, Kergoat (2010) discorre sobre o trabalho do care, que geralmente recai sobre as mulheres negras e pobres:

As três relações são inseparáveis e não somente se reforçam, mas se co-produzem mutuamente: a radicalização, à qual os empregos domésticos estão particularmente sujeitos, reforça e legitima a precarização (e, portanto, as relações de classe) e a "generização"; a relação de gênero exacerba a relação de classe na medida em que a feminização dessas últimas é um fenômeno novo para o corpo social e, portanto, para o qual ainda não há uma resposta, e reforça as relações de raça pela sua naturalização. (KERGOAT, 2010, p. 11)

Diante das questões relatadas e exemplificadas, acreditamos que a posição das mulheres trabalhadoras no sistema publicitário é consubstancial, fazendo com que sofram coextensivamente com as questões de gênero, "raça" e classe. Para subverter essa realidade em operação, as ações no sistema publicitário devem ser coletivas, afetando as relações sociais para além das intersubjetivas. Só assim a exploração, a dominação e a opressão poderão ser minimizadas.

Conseguimos encontrar ações de publicitárias comprometidas com a coletividade das profissionais da área. Um exemplo é o projeto “\#PretasNaPublicidade”, desenvolvido pela consultoria feminina 65/10, que visa incentivar o ingresso de mulheres negras na faculdade de publicidade e na área de criação. $\mathrm{O}$ aumento da presença de mulheres negras na publicidade e no setor criativo contribui para a quebra da visão hegemônica e homogênea do homem branco e heteronormativo como construtor das mensagens publicitárias. Assim, acredita-se que as representações das mulheres, principalmente negras, poderão ser mais próximas da realidade e menos estigmatizadas.

Aumentar e melhorar a representação das mulheres negras na mídia contribui para o empoderamento desse grupo, como comenta Berth (2019). Empoderamento, segundo a autora, é um despertar da consciência, acometido pela autoafirmação, autovalorização, autorreconhecimento, autoconhecimento, das mais variadas habilidades humanas, de sua história e, principalmente, de um entendimento da posição social e política, do qual deriva um estado psicológico perceptivo do que se passa ao redor. Assim, a publicidade poderia atuar como uma ferramenta emancipatória, tanto para as trabalhadoras publicitárias quanto para as receptoras/consumidoras, que ao se enxergarem em diferentes papéis podem passar por um processo de ajuda e de autodireção.

Outros dois projetos que auxiliam na visibilidade e representação das mulheres na sociedade, criados por publicitárias que desejam melhorar as relações de trabalho no setor e a representação das mulheres em propagandas, são os bancos de imagens "Mulheres (In)Visíveis", criado pela consultoria 65/10, e "Young Gifted and Black", criado pela publicitária Joana Mendes. Essas plataformas disponibilizam fotos para serem utilizadas em campanhas publicitárias com representações de diversas performances de mulheres (BUTLER, 2003), sendo a última destinada exclusivamente a mulheres negras.

A ação do coletivo More Glrs, responsável por mapear talentos femininos nas áreas de publicidade, design e conteúdo, também fomenta 
esse movimento. $\mathrm{O}$ objetivo é dar visibilidade às criativas que estão no mercado, oferecendo consultoria de headhunter, de eventos, de awareness e de trato organizacional (MINUZZI, 2020).

Há ainda o projeto \#PlanoDeMenina, criado pela consultoria dedicada à capacitação de profissionais do gênero feminino Plano Feminino, que promove ações de inclusão e capacitação a meninas de periferia em pontos do Brasil. Mesmo que não seja um projeto direcionado ao mercado publicitário, a idealizadora da consultoria é jornalista, e comenta que a luta de gênero e classe deve ser combatida desde a infância (MINUZZI, 2020). Por último, em 2020, a consultoria “Indique Uma Preta”, responsável por promover conexões entre mulheres negras e o mercado de trabalho, passou a contar com o suporte da agência de publicidade Mutato, que fornece apoio técnico e gerencial para que a consultoria cresça.

Diante das ações listadas, é possível perceber que há mobilizações coletivas, comprometidas com mudanças nas estruturas das relações sociais, para além das relações intersubjetivas, levando em consideração a problemática da consubstancialidade entre as trabalhadoras publicitárias no mercado do trabalho e as questões de exploração, dominação e opressão.

\section{CONSIDERAÇÕES FINAIS}

Neste artigo, tivemos como intenção responder à seguinte questão: de que maneira é possível empregar o conceito da consubstancialidade nas pesquisas em publicidade? Ainda que sejam necessários estudos mais amplos para chegarmos a uma resposta definitiva, fizemo-nos essa pergunta considerando, especialmente, as questões relacionadas a esse marcador social das diferenças. Inicialmente, apresentamos a importância de se explorar as questões de gênero nas pesquisas em publicidade, entendendo a necessidade de olhar para outras áreas do sistema publicitário além do produto.

Assim, podemos dizer que as formas mais adequadas de empregar o conceito da consubstancialidade nas pesquisas em publicidade são: acioná-lo nas pesquisas interessadas em desbravar questões trabalhistas no sistema publicitário, e que são impactadas pelas relações sociais de gênero, "raça" e classe dentro da indústria criativa. Neste caso, por exemplo, as pesquisas podem ser direcionadas para profissionais de publicidade que têm a possibilidade de atuar em agências, ou como freelancers, em universidades como docentes, ou até mesmo em pesquisas que explorem os motivos pelos quais os e as profissionais abandonam a profissão.

Vale ressaltar que esse conceito se torna relevante porque proporciona a possibilidade de pensar as relações sociais de gênero, "raça" e classe a partir do imperativo materialista, já que analisa como acontece a apropriação do trabalho de um grupo pelo outro, o que obriga, segundo Kergoat (2010), a pensar nas disputas dessas relações sociais. As disputas das relações sociais refletem na divisão sexual do trabalho, o que se demonstra pela predominância de homens brancos heteronormativos nos espaços privilegiados, com maior concentração de poder, salários mais altos e nas áreas de atuação de mais prestígio. Em contraponto, as mulheres ocupam cargos que não recebem tanto reconhecimento, os salários são mais baixos e a maternidade ainda é vista como empecilho no mercado publicitário. Às mulheres negras e de classe mais baixas, são relegados os piores cargos, reforçando as estruturas da desigualdade social. 
Outro ponto que merece destaque é entender que as relações sociais de gênero, "raça" e classe são consubstanciais, formando um nó que não pode ser desatado no nível das práticas sociais, já que essas relações são coextensivas. Portanto, acreditamos que o termo consubstancialidade pode ser uma alternativa fértil para os estudos em publicidade, principalmente em pesquisas que desejam observar as relações de trabalho na instância de produção publicitária.

\section{REFERÊNCIAS}

5 PERGUNTAS para Keka Morelle. Creative X, Wired Festival, Globo.com. 5 set. 2019. Disponível em: https://bit.ly/3u4R4eR. Acesso em: 18 ago. 2020.

BUTLER, Judith. Problemas de gênero: feminismo e subversão da identidade. Tradução de Renato Aguiar. Rio de Janeiro: Civilização Brasileira, 2003.

CARNEIRO, Sueli. Mulheres em movimento: contribuições do feminismo negro. In: HOLLANDA, Heloísa Buarque de (org.). Pensamento feminista brasileiro: Formação e contexto. Rio de Janeiro: Bazar do Tempo, 2019.

CRENSHAW, Kimberlé Williams. Mapping the margins: intersectionality, identity politics, and violence against women of color. In: Fineman, Martha Albertson; Mykitiuk, Roxanne (eds.). The public nature of private violence. New York: Routledge, 1994. p. 93-118.

DAVIS, Angela. Women, Race and Class. New York: Random House, 1981.

ELA SE TORNOU a primeira diretora negra em uma grande agência publicitária. Universa Talks. São Paulo, 16 jul. 2020. Disponível em: https://bit.ly/2SXX2Be. Acesso em: 26 ago. 2020.

FOUCAULT, Michel. Em defesa da sociedade: curso dado no Collège de France (1975-1976). São Paulo: Martins Fontes, 2005.

GRUPO DE PLANEJAMENTO. Hostilidade, Silêncio e Omissão. 2019. Disponível em https:// bit.ly/3467itm. Acesso em: 18 ago. 2020.

HANSEN, Fábio; WEIZENMANN, Cátia. Elas não querem criar? Apontamentos sobre a institucionalização do trabalho de criação publicitária no mercado de Porto Alegre. Comunicação \& Informação, Goiânia, v. 18, n. 1, p. 21-36, 2015.

HENNING, Carlos. Interseccionalidade e pensamento feminista: as contribuições históricas e os debates contemporâneos acerca do entrelaçamento de marcadores sociais da diferença. Mediações, Londrina, v. 20 n. 2, p 97-128, jul./dez. 2015.

HIRATA, Helena. Gênero, classe e raça: Interseccionalidade e consubstancialidade das relações sociais. Tempo Social, São Paulo, v. 26, n. 1, p. 61-73, jun. 2014. Disponível em: https://bit.ly/3oHBi8l. Acesso em: 28 jul. 2020.

KERGOAT, Danièle. Dinâmica e consubstancialidade das relações sociais. Novos Estudos Cebrap, São Paulo, v. 86, p. 93-103, 2010. Disponível em: https://bit.ly/33YLXIT. Acesso em: 17 jul. 2020.

MINUZZI, Carolina. Uma genealogia das mulheres no sistema publicitário brasileiro. Dissertação (Mestrado em Comunicação) - Universidade Federal de Santa Maria. Santa Maria, 2020.

PETERMANN, Juliana. Do sobrevôo ao reconhecimento atento: a institucionalização da criação publicitária, pela perspectiva do habitus. 2011. Tese (Doutorado em Ciências da Comunicação) - Universidade do Vale dos Sinos, São Leopoldo, 2011.

PISCITELLI, Adriana. Interseccionalidade, categorias de articulação e experiências de migrantes brasileiras. Sociedade e Cultura, Goiânia, v. 11, n. 2, p. 263-274, 2018.

SACCHITIELLO, Bárbara; LEMOS, Alexandre Zaghi. Mulheres são 20\% da criação das agências. Meio e Mensagem, São Paulo, 12 jan. 2016. Disponível em: https://bit.ly/3f1H2H4. Acesso em: 18 ago. 2020.

SPAULUCCI, Neusa. Participação feminina é minoritária na liderança criativa das agências. Propmark, São Paulo, 2 mar. 2020. Disponivel em: https://bit.ly/3bHsM41. Acesso em: 10 ago. 2020.

TOMAZETTI, Tainan. Genealogias dissidentes: os estudos de gênero nas teses e disser- 
tações em comunicação do Brasil (1972-2015). 2019. Tese (Doutorado em Comunicação e Informação) - Universidade Federal do Rio Grande do Sul, Porto Alegre, 2019.

TRINDADE, Eneus. Tendências para pensar a formação em publicidade da contemporaneidade. Revista Latinoamericana de Ciencias de la Comunicación, São Paulo, v. 14, n. 27, p. 32-41, 2017. Disponível em: https://bit.ly/3oB6Xsr. Acesso em: 3 jul. 2020. 